\title{
Plagiarism and Copyright Violation
}

\author{
Samuel J. Stratton, MD, MPH
}

Plagiarism and copyright violation are commonplace unethical practices in medical science. Because electronic formats allow the rapid, non-reviewed posting of information, plagiarism and copyright violations on the Internet are a particular issue.

Plagiarism is taking the writings of another and claiming them as one's own. Plagiarism is considered a serious breach of ethics among scientists, but this does not deter some individuals. This practice is unethical and damaging to others for a number of reasons. Plagiarism:

(1) is a form of scientific fraud;

(2) is stealing another's work;

(3) causes emotional and personal distress to the original author(s);

(4) may be a means to fraudulent economic gain; and

(5) is often committed to advance one's academic standing at the expense of others.

In addition, plagiarism exposes a lack of integrity on the part of the plagiarist, and therefore a possible tendency of the person committing the plagiarism to present fraudulent academic and scientific work.

Public discussion and exposure of confirmed plagiarism is an appropriate approach for controlling the problem; the corrective action when plagiarized material has been published is well established. Accepted practice is for the individual who has made the mistake to contact the editor of the journal that published the plagiarized material and discuss possible solutions. ${ }^{1}$ Often, a journal editor must confront a plagiarist, and request a formal retraction of the plagiarized material, along with a written apology and acknowledgment of the act.

As with other medical journals, authors recently published in Prehospital and Disaster Medicine (PDM) have been victims of plagiarism. An example is the article "Future Humanitarian Crises: Challenges for Practice, Policy, and Public Health," authored by Dr. Frederick Burkle in 2010. ${ }^{2}$ After the original article was published in $P D M$, the content of the article was published verbatim on Internet sites without the Journal's permission. ${ }^{3}$ The owner of these Web sites took credit for writing the material, and failed to credit Dr. Burkle and PDM with originally publishing the work. Prehospital and Disaster Medicine appropriately notified the Web site owner of his copyright infringement, but did not receive a reply. After some delay, the articles were deleted from the Web sites. The plagiarist made no apology, offered no formal retraction, and did not acknowledge the mistake, although these actions are necessary to protect the integrity of the actual author and journal. This failure to formally retract and to acknowledge the plagiarism led to further damage for the actual author. Dr. Burkle discovered that the original PDM article appeared on sites used to check for plagiarism with a running message under the content of the article reading "Author [Dr. Burkle] suspected of plagiarism." In attempting to recover his reputation, Dr. Burkle was forced to obtain legal assistance, costing him considerable time and expense. Ironically, the plagiarist did not suffer from his act.

Self-plagiarism, or submission of one's previously published work as original and unpublished, is another form of plagiarism recently encountered by $P D M$ editorial staff. This year, two authors have submitted manuscripts that were verbatim versions of their copyright-protected articles previously published by online medical journals. This type of plagiarism is a particular risk for medical journals because unknowingly publishing material that has been copyright protected creates a legal liability for the journal. Duplicate or redundant publication of a paper may benefit the authors, but for the second journal to publish the paper is a violation of copyright law. Authors are required by publishers to attest that a manuscript is original and not previously published, and to transfer to publishers the copyright to material that is to be published. In order to publish a duplicate manuscript, an author must falsely attest to the work being original and unpublished, as well as illegally transfer a copyright that is the property of the original publisher.

There is also confusion about plagiarism and proper citation of previous work. In fact, using citations and references to previous writing and ideas to support original work is an accepted foundation of proper scientific research and writing. It is standard in medical scientific writing that when another author's exact phrase, sentence, or paragraph is used, the original words are enclosed with quotation marks along with a proper reference citation. The solution to avoiding plagiarism and copyright violation is proper acknowledgment of any previous work used to support one's original writings. Referencing previous work in research builds robustness into scientific methodology; stealing another's work and passing it off as one's own is theft and fraud.

Recently, the journal Nature published a series on "How to Stop Plagiarism" that called for journals to check manuscripts for plagiarism upon submission. ${ }^{4} P D M$ has adopted as a standard the electronic scanning for plagiarism of manuscripts submitted to the Journal. While scanning slows the processing of manuscripts, it is necessary because of the risk for plagiarism.

More difficult than detecting plagiarism in submitted manuscripts is finding and addressing plagiarism of original articles published in PDM. For future confirmed cases, it will be the practice of the Journal to contact the person who committed the act to discuss a remedy that will include a request for a written acknowledgement and apology to the actual author. If requests for correction of the act are ignored, the appropriate action for protection of the original author and $P D M$ is public exposure of the plagiarist.

The Prehospital and Disaster Medicine editorial staff views all forms of plagiarism as serious, and will take any actions necessary to prevent, detect and correct this kind of fraud. 
References

1. World Association of Medical Editors. Plagiarism. www.wame.org/resources/ publication-ethics-policies-for-medical-journals\#plagiarism. Accessed August 4, 2012.

2. Burkle FM. Future humanitarian crises: challenges for practice, policy, and public health. Prehosp Disaster Med. 2010;25(3):191-199.

3. Noji E. Humanitarian futures: first of a five-part series. Previously available at http://www.thecausetv.com/2010/08/humanitarian-futures-series-part-1-of-5.html.
4. Editorial Comment. Science publishing: how to stop plagiarism. Nature. 2012; 481(7379):21-23.

doi:10.1017/S1049023X12001264 